\title{
Torque Control of Switched Reluctance Motors
}

\author{
C. Moron ${ }^{1}$, A. Garcia ${ }^{1}$, E. Tremps ${ }^{1}$ and J. A. Somolinos ${ }^{2}$ \\ ${ }^{1}$ E.U. Arquitectura Técnica (U.P.M.), Sensors and Actuators Group, Madrid, Spain \\ ${ }^{2}$ ETS Ingenieros Navales (U.P.M.), Madrid, Spain
}

\begin{abstract}
This paper presents the performance of an instantaneous torque control method. The simulation and experimental results illustrate the capability of Switched Reluctance Motors (SRM) being used in the motor drive industry. Based on experimental data, the advantages of this control method and its disadvantages in practical implementation were studied. The model used in the simulation is the linear magnetic model which has the $12 / 8$ structure, the same structure as the experimental switched reluctance motor.
\end{abstract}

Index Terms-Reluctance Motors, Torque Control.

\section{INTRODUCTION}

$\mathrm{T}$ HE SWITCHED Reluctance Motor (SRM) is an old member of the electric machine family. The first SRM can be traced back to the early 19th century [1]. The main advantages of SRM are their simple structure, ruggedness, and that they are relatively inexpensive to manufacture. However, the primary disadvantages, such as the torque ripple, acoustic noise, and the difficulty in controlling, prevent it from being accepted by the industry extensively.

During the past two decades, researches have been done to reduce the torque ripple and acoustic noise. Several rather complicated control methods, motor designs, and power electronics inverter topologies have been proposed which now make the SRM a possible candidate for many drive applications, such as servo drives and traction drives of Hybrid Electric Vehicles (HEVs) [2] [3] [4] [5] [6] [7].

\section{SWitched RELUCTANCE Motor Drive}

\section{1) Basic Structure}

Figure 1 illustrates a 6/4 SR motor with a rotor tooth pair aligned with stator phase A - A'. In Figure 1, the rotor is aligned with stator phase $\mathrm{A}-\mathrm{A}^{\prime}$ and this is said to be at the aligned position for stator phase $\mathrm{A}-\mathrm{A}^{\prime}$. The aligned position is a stable equilibrium point in that the phase current can not produce any torque at this position, but a small deviation of the rotor away from this point will produce a torque to push the rotor back. In contrast, the unaligned position is an unstable equilibrium point because any small displacement of the rotor away from that point results in the rotor moving away.

Figure 2 illustrates the periodic change of inductance versus rotor position assuming that no saturation exists (A linear magnetics model). $\beta_{\mathrm{s}}$ denotes the stator pole-arc and $\beta_{\mathrm{r}}$ denotes the rotor pole-arc. The abscissa of Figure 2 is the mechanical rotor position. $\tau_{\mathrm{r}}$ denotes the absolute torque zone within which a phase can produce non-zero torque. The angles $\beta_{\mathrm{s}}, \beta_{\mathrm{r}}$ are also indicated in Figure 1, which gives a more geometric view of these definitions.

\section{FIG. 1 HERE}

In Figure 2, $\theta_{2}$ is the angle where the overlapping of the stator and rotor poles occurs. Before this position, the phase inductance keeps its minimum value $\mathrm{L}_{\text {min }} . \theta_{3}$ is the position where the stator pole-arc $\beta_{\mathrm{s}}$ becomes fully overlapped with the rotor pole-arc $\beta_{\mathrm{r}}$. Between the position $\theta_{2}$ and $\theta_{3}$, the phase inductance increases linearly as the rotor moves. From $\theta_{4}$, the full overlapping of the stator and rotor poles ends and the phase inductance decreases linearly until the rotor reaches the position $\theta_{5}$ where no overlapping exists and the phase inductance becomes $L_{\min }$ again. The interval between $\theta_{3}$ and $\theta_{4}$ is termed "dead zone". During this interval, the phase inductance keeps its maximum value $L_{\max }$. If $\beta_{\mathrm{r}}$ is equal to $\beta_{\mathrm{s}}$, there is no "dead zone". The 6/4 SR motor illustrated in Figure 1 is of this kind, that is, does not have "dead zone".

\section{FIG. 2 HERE}

\section{2) The SMR Model}

The expressions for the flux linkages of the different phases are just shifted by $\theta_{\mathrm{s}}=2 \pi / \mathrm{qn}_{\mathrm{R}}$. For the three-phase SRM, the electrical equations are given by:

$$
\begin{aligned}
& \frac{d}{d t} \phi\left(n_{R} \theta, i_{a}\right)=-i_{a} R+v_{a} \\
& \frac{d}{d t} \phi\left(n_{R} \theta-\theta_{S}, i_{b}\right)=-i_{b} R+v_{b} \\
& \frac{d}{d t} \phi\left(n_{R} \theta-2 \theta_{S}, i_{c}\right)=-i_{c} R+v_{c}
\end{aligned}
$$

The mechanical equation of the SRM is

$$
J \frac{d \omega}{d t}+B \omega=\tau\left(n_{R} \theta, i_{a}, i_{b}, i_{c}\right)-\tau_{L}
$$

where $\mathrm{J}$ is the motor inertia, B is the viscous coefficient and $\tau_{\mathrm{L}}$ is the load torque and the torque is given by

$$
\tau\left(n_{R} \theta, i_{a}, i_{b}, i_{c}\right)=\tau_{a}\left(n_{R} \theta, i_{a}\right)+\tau_{b}\left(n_{R} \theta, i_{b}\right)+\tau_{c}\left(n_{R} \theta, i_{c}\right)
$$

\footnotetext{
Manuscript received January 1, 2008 (date on which paper was submitted for review). Corresponding author: F. A. Author (e-mail: f.author@nist.gov).

Digital Object Identifier inserted by IEEE
} 


$$
\begin{aligned}
& \tau_{a}\left(n_{R} \theta, i_{a}\right)=f\left(n_{R} \theta, i_{a}\right)=\frac{\partial}{\partial \theta} \int_{0}^{i_{a}} \phi\left(n_{R} \theta, i_{a}^{\prime}\right) d i_{a}^{\prime} \\
& \tau_{b}\left(n_{R} \theta, i_{b}\right)=f\left(n_{R}\left(\theta-\theta_{S}\right), i_{b}\right)=\frac{\partial}{\partial \theta} \int_{0}^{i_{b}} \phi\left(n_{R}\left(\theta-\theta_{S}\right), i_{b}^{\prime}\right) d i_{b} \\
& \tau_{c}\left(n_{R} \theta, i_{c}\right)=f\left(n_{R}\left(\theta-2 \theta_{S}\right), i_{c}\right)=\frac{\partial}{\partial \theta} \int_{0}^{i_{c}} \phi\left(n_{R}\left(\theta-2 \theta_{S}\right), i_{c}^{\prime}\right) d i_{c}
\end{aligned}
$$

Expanding equations (1) gives

$$
\begin{aligned}
\frac{d i_{a}}{d t} & =\left(-i_{a} R-\frac{\partial}{\partial \theta} \phi\left(n_{R} \theta, i_{a}\right) n_{R} \omega+v_{a}\right) / \frac{\partial}{\partial i_{a}} \phi\left(n_{R} \theta, i_{a}\right) \\
\frac{d i_{b}}{d t} & =\left(-i_{b} R-\frac{\partial}{\partial \theta} \phi\left(n_{R}\left(\theta-\theta_{S}\right), i_{b}\right) n_{R} \omega+v_{b}\right) / \frac{\partial}{\partial i_{b}} \phi\left(n_{R}\left(\theta-\theta_{S}\right), i_{b}\right) \\
\frac{d i_{c}}{d t} & =\left(-i_{c} R-\frac{\partial}{\partial \theta} \phi\left(n_{R}\left(\theta-2 \theta_{S}\right), i_{c}\right) n_{R} \omega+v_{c}\right) / \frac{\partial}{\partial i_{c}} \phi\left(n_{R}\left(\theta-2 \theta_{S}\right), i_{c}\right)
\end{aligned}
$$

Equation (5) shows that if the flux linkage $\phi(\theta, i)$ is known (for $0 \leq \theta \leq \pi / n_{R}$, symmetry of the motor structure is guaranteed), the electrical equations of a SRM is then determined.

For establishing a linear magnetics model we define $\mathrm{L}(\theta)$ with their Fourier series and then gives the instantaneous torque simply as

$$
\tau\left(n_{R} \theta, i\right)=\frac{1}{2} i^{2} \frac{d L\left(n_{R} \theta\right)}{d \theta}=\frac{1}{2} i^{2} n_{R} \sum_{k=1}^{\infty} k a_{k} \sin \left(k n_{R} \theta\right)
$$

In this form, a Fourier Series of $\mathrm{L}(\theta)$ up to third harmonics is given as

$$
\begin{aligned}
& L_{j}\left(n_{R} \theta\right)=a_{0}-\sum_{k=1}^{3} a_{k} \cos \left[k n_{R}\left(\theta-(j-1) \theta_{S}\right)\right] \\
& \phi_{j}\left(n_{R} \theta\right)=\left\{a_{0}-\sum_{k=1}^{3} a_{k} \cos \left[k n_{R}\left(\theta-(j-1) \theta_{S}\right)\right]\right\} i_{j} \\
& \tau_{j}\left(n_{R} \theta, i_{j}\right)=\frac{1}{2} i_{j}^{2} n_{R} \sum_{k=1}^{3} k a_{k} \sin \left[k n_{R}\left(\theta-(j-1) \theta_{S}\right)\right]
\end{aligned}
$$

where $\mathrm{j}=1,2,3$ stands for phase A,B,C, respectively, and the coefficients are given as $\mathrm{a}_{0}=0.03, \mathrm{a}_{1}=0.0222, \mathrm{a}_{2}=0.0004$ and $\mathrm{a}_{3}=0.0011$.

\section{FIG. 3 HERE}

Figure 3 shows the transient torque waveform of SRM. The model used in the simulation is the linear magnetic model which has the $12 / 8$ structure, the same structure as the experimental switched reluctance motor. For the simulation described, the number of rotor poles is set as $n_{R}=4$ in the two step response to make it coincident with the 6/4 SRM illustrated in Figure 1 and Figure 2.

\section{FIG. 4 HERE}

Figure 4 plots the inductance and phase torques of this specific model with $n_{R}=8$ between $0^{0}-90^{0}$, where the torque is calculated with constant phase current $\mathrm{I}=2.5 \mathrm{~A}$.

\section{TORQUe CONTROL METHOD}

For the SRM application in servo systems, one of the control purposes is to reduce the torque ripple that inherently exists in the average torque control. In average torque control, the current references of two subsequent phases are designed independently, i.e., the current profile between two subsequent phase excitations is not controlled. Therefore, high torque ripple will occur during commutation. Also, the flat top of the current shape is expected to produce torque ripple.

To reduce or even eliminate the torque ripple, the control of the torque at each instant in time is considered. Wallace and Taylor [8] presented an instantaneous torque control method which is the control method implemented in this work. This control method, like all the other advanced torque control methods, assumes that a perfect current tracking is realized by current tracking loop. Therefore, the task of control is to define the reference current such that the desired torque is tracked instantaneously.

\section{FIG. 5 HERE}

Figure 5 shows a simulation result of this control method tracking a constant torque reference $\tau^{\mathrm{d}}$, where the model is the 3-phase 12/8 SRM defined in section 2. As shown in the figure, the commutation angle $\theta_{\mathrm{c}}$ is defined as the position where the two adjacent phases can produce the same torque with the same current in their windings. In the interval $\left[\theta_{c}^{j}\right.$, $\left.\theta_{\mathrm{c}}^{\mathrm{j}}+\theta_{\mathrm{s}}\right]$, phase $\mathrm{j}$ is the strong phase that can produce the largest torque of desired polarity for a given current. The current reference of phase $\mathrm{j}-1$ is designed to decrease to zero linearly in the interval $\left[\theta_{c}^{j}, \theta_{z}^{j-1}\right]$ so that it is brought to zero before it can produce negative torque. The current reference of phase $j$ before $\theta_{c}^{j}$ is designed to increase linearly from zero to $i_{j}\left(\theta_{c}^{j}\right)=$ $\mathrm{g}\left(1 / 2 \tau^{\mathrm{d}}\left(\theta_{\mathrm{c}}^{\mathrm{j}}\right), \theta_{\mathrm{c}}^{\mathrm{j}}\right)$. The function $\mathrm{i}=\mathrm{g}(\tau, \theta)$ is obtained by inverting experimentally determined function $\tau(\theta$, i). As the rotor position increases, phase $\mathrm{j}+1$ will take the place of phase $\mathrm{j}$ to be the strong phase at position $\theta_{\mathrm{c}}^{\mathrm{j}}+\theta_{\mathrm{s}}$. Then the reference current of phase $\mathrm{j}$ is commutated at $\theta_{\mathrm{c}}^{\mathrm{j}}+\theta_{\mathrm{s}}$ and goes to zero linearly and phase $\mathrm{j}+1$ becomes the phase that produces the desired torque. During the strong period, e.g., the interval $\theta_{c}^{j}$ $\rightarrow \theta_{\mathrm{c}}^{\mathrm{j}}+\theta_{\mathrm{s}}$ for phase $\mathrm{j}$, the current reference is defined by $\mathrm{i}_{\mathrm{j}}(\theta)=$ $\mathrm{g}\left(\tau_{\mathrm{j}}^{\mathrm{d}}(\theta), \theta\right)$, with $\tau_{\mathrm{j}}^{\mathrm{d}}(\theta)=\tau^{\mathrm{d}}(\theta)-\tau_{\mathrm{j}-1}(\theta)-\tau_{\mathrm{j}+1}(\theta)$, to track the desired torque $\tau^{\mathrm{d}}$ instantaneously.

The reference current design of this control method is to have the strong phase produce the commanded torque. Thus the torque per ampere ratio of this control method is high. However, it does not reach the maximum torque per ampere ratio because the current changes linearly with respect to $\theta$ during the commutation.

An alternative instantaneous torque control method is to define $\theta_{c}$ at the position where two adjacent phases produce the same torque with the same flux linkage in their windings. Instead of defining the current reference, flux linkage reference is defined in a similar way to the maximum torque per ampere control. Such a control method is called maximum torque per flux control, which implies that it will reduce the required phase input voltage for the same desired torque, compared to the maximum torque per ampere control. 


\section{EXPERIMENTAL RESULTS}

The torque-angle characteristic $\tau(\theta, i)$ is obtained by an automatic identification procedure in which the position of the shaft of the system is controlled precisely by the PM synchronous motor to increment in steps of $0.9^{\circ}$ for an entire mechanical revolution $\left(360^{\circ}\right)$. With a constant current kept in one phase of the SRM, the torque is measured by the torque transducer. The phase current is the increased in steps of $0.24 \mathrm{~A}$ and the procedure repeated until the current reaches the limit current.

A quadrature encoder is used for measuring incremental angular position. Because the position $\theta$ is measured in encoder counts $(0 \rightarrow 4000$ for one revolution $)$, the inherent error of $\theta$ is $360^{\circ} / 4000=0.09^{\circ}$. It turns out that if the step size of the position reference trajectory is not an integer times $0.09^{\circ}$, the actual shaft trajectory would oscillate between $\pm 0.09^{\circ}$. Therefore, the step size of the position reference here is chosen to be $0.9^{\circ}$ (or 10 encoder counts). The torque is measured at 400 points per revolution.

For the 3-phase 12/8 SR motor, the experimental torqueangle characteristic for $\theta \in\left[0,22.5^{\circ}\right]$ is extracted from Figure 6 . The resulting look-up table for $\tau(\theta, \mathrm{i})$ is a $10 \times 25$ matrix. Figure 7 give the 2-D plot of this look-up table.

\section{FIG. 6 HERE}

A comparative study between several methods has been done with the experimental $12 / 8 \mathrm{SR}$ motor in fig. 7. Figure 7 (a) shows the torque control with conventional sinusoidal control while figure 7 (b) is the torque result when method from [9] is implemented in the same motor. In this last case the controller is adopted for the sake of performance comparison. It can clearly see how the proposed instantaneous torque control reduces the torque ripple.

\section{FIG. 7 HERE}

\section{CONCLUSION}

The torque ripple of the SRM is due to the doubly salient structure of the machine. The existence of the torque dip between two subsequent phases dictates the existence of torque ripples.

The idea of the control method implemented in this work is to define the commutation angle $\theta_{c}$, at which two adjacent phases can produce the same torque for same current. Based on the defined $\theta_{c}$, specific current references for commutation are designed, which is theoretically able to eliminate the torque ripple due to the torque dip. Because the control method assigns the strong phase to produce desired torque as much as possible, it assures low currents in phases other than the strong phase, which achieves a secondary objective of minimizing the copper losses.

The control method leads to a reduction in the average torque. The maximum commanded torque of the strong phase must be less than a certain level which is less than the peak of the torque profile, to avoid the torque ripple due to the shape of the torque profile (see Figure 7). Therefore, the average torque under this controller has to be less than the rated average torque.

In the future, it will be interesting to obtain robust controllers in order to minimize the non desired torque ripple (due to its non-linearity) which let use this kind of motors as drive trains for prototype electric cars. This is the subject of our current research.

\section{ACKNOWLEDGMENT}

This work was supported in part by the Universidad Politécnica de Madrid.

\section{REFERENCES}

[1] T.J.E. Miller, Switched Reluctance Motors and their Control, Magna Physics Publishing, 1993.

[2] T.J.E. Miller, .Optimal design of switched reluctance motors, IEEE Transactions on Industrial Electronics, vol. 49, no. 1, 2002, pp. 15-26.

[3] David A. Torrey, .Switched reluctance generator and their control, IEEE Transactions on Industrial Electronics, vol. 49, no. 1, 2002, pp. 3-13.

[4] Robert B. Inderka, Marcus Menne, and Rik W.A.A. De Doncker, Control of switched reluctance drives for electric vehicle applications, IEEE Transactions on Industrial Electronics, vol. 49, no. 1, 2002, pp. 48-52.

[5] Mehrdad Ehsani and Babak Fahimi, .Elimination of position sensors in switched reluctance drives: State of the art and future trends, IEEE Transactions on Industrial Electronics, vol. 49, no. 1, 2002, pp. 40-46.

[6] Chang-Hwan Kim and In-Joong Ha, .A new approach to feedbacklinearizing control of variable reluctance motors for direct-drive applications, IEEE Transactions on Control Systems Technology, vol. 4, no. 4, 1996, pp. 348-362.

[7] Patrick L. Chapman and Scott D. Sudhoff, .Design and precise realization of optimized current waveforms for an $8 / 6$ switched reluctance drive, IEEE Transactions on Power Electronics, vol. 17, no. 1, 2002, pp. 76-83.

[8] R.S. Wallace and D.G. Taylor, .A balanced commutator for switched reluctance motors to reduce torque ripple,. IEEE Transactions on Power Electronics, vol. 7, no. 4, October 1992.

[9] S.-K. Chung, H.-S. Kim, C.-G. Kim, and M.-J. Youn, "A new instantaneous torque control of PM synchronous motor for high performance direct drive applications," IEEE Trans. Power Electron., vol. 13, no. 3, pp. 388-400, May 1998. 


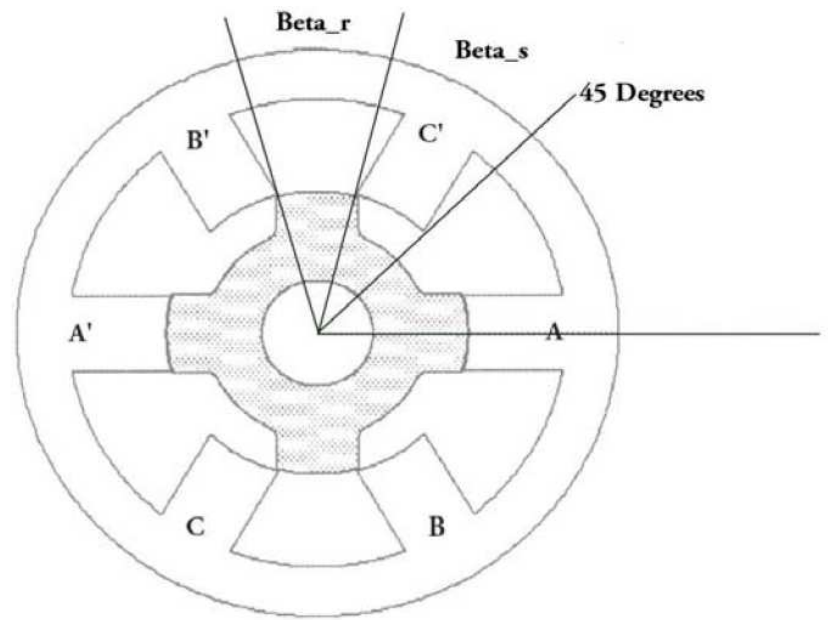

Fig. 1. Cross section of a 6/4 SR motor (Phase A is at Aligned Position).

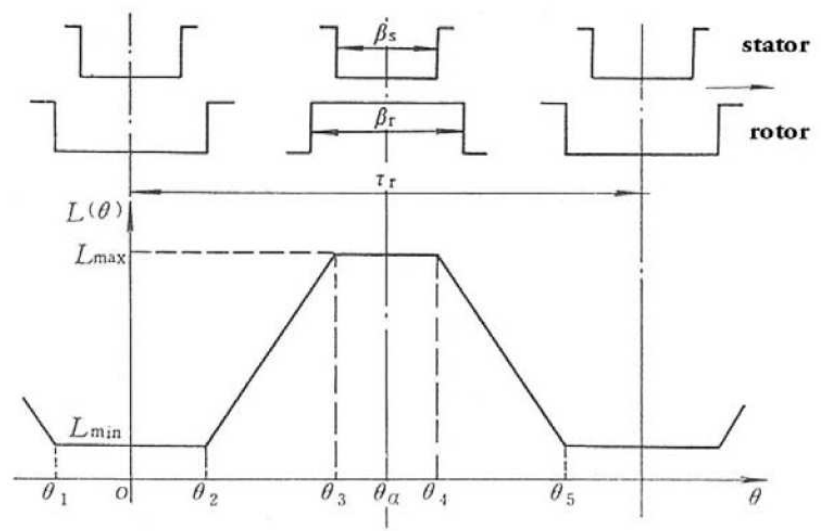

Fig. 2. Inductance vs Rotor Position for a constant current.

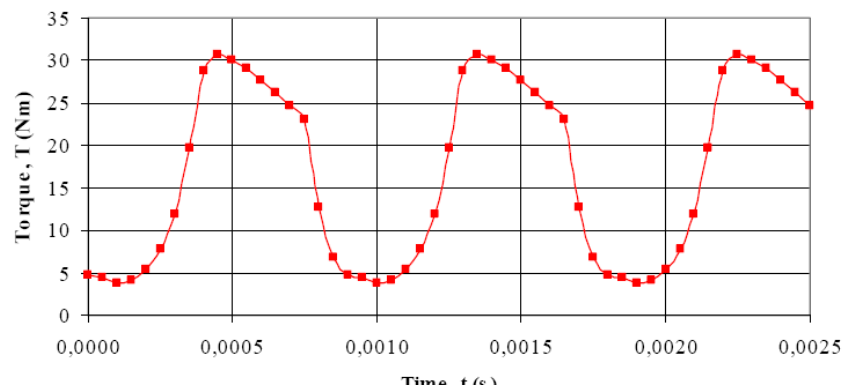

Fig. 3. Transient torque waveform of $12 / 8 \mathrm{SRM}$.
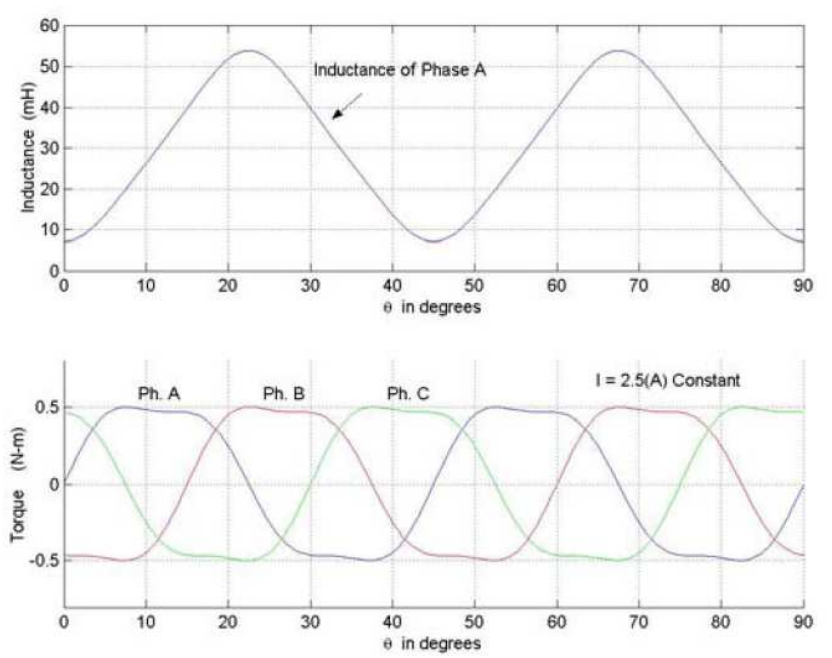

Fig. 4. Inductance and torque versus rotor obtained with the simulation.

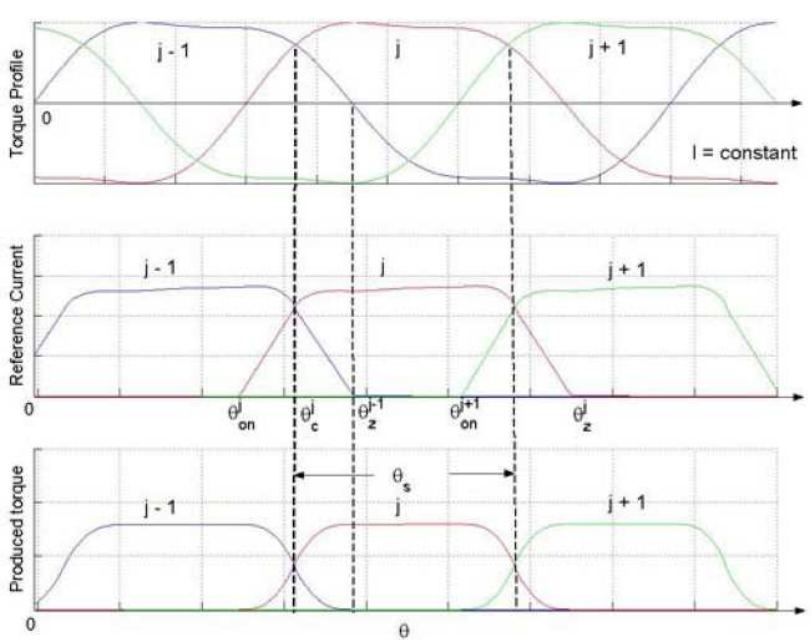

Fig. 5. Example of the reduced torque ripple control.

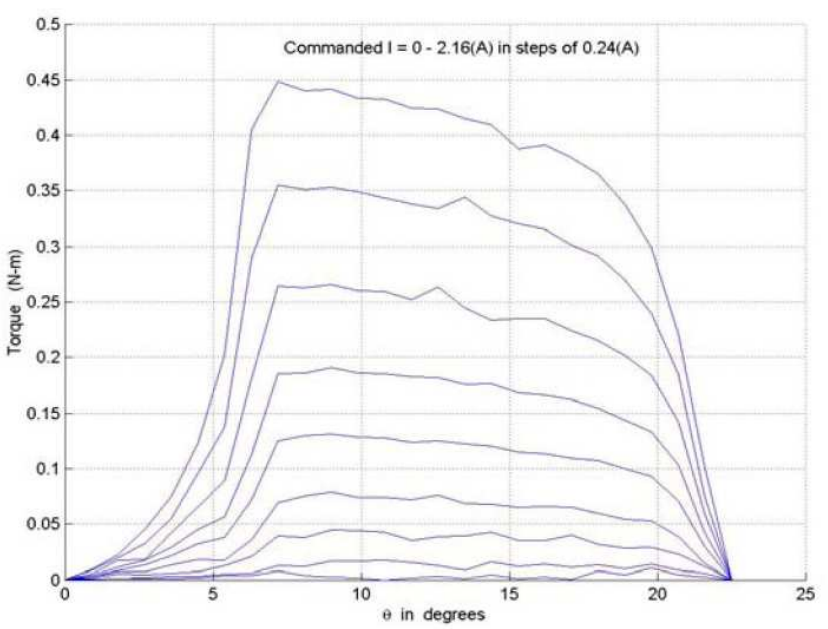

Fig. 6. Experimentally Measured $\tau\left(\theta\right.$, i) of Phase A for $0^{\circ} \leq \theta \leq 22.5^{\circ}$. 


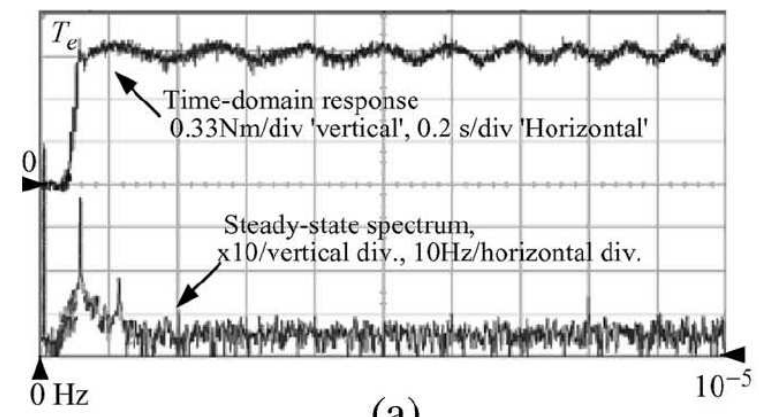

(a)

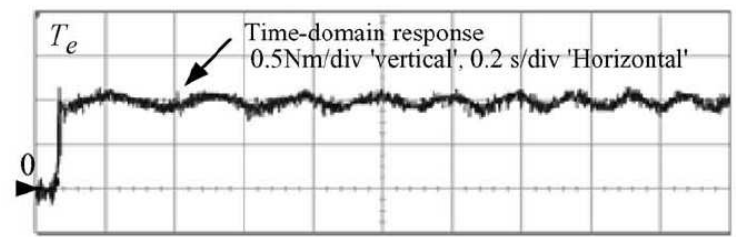

(b)

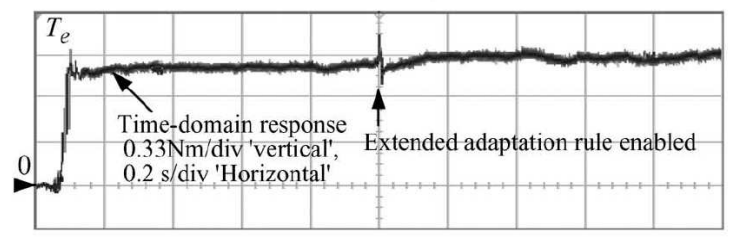

(c)

Fig. 7. Torque response of SRM when it is controlled by: (a) Conventional sinusoidal. (b) The sake of performance comparison detailed in [9]. (c) The proposed instantaneous torque control. 